Britain does not have collective agreements as intensive in coverage as those existing in the United States: perhaps owing to the extensiveness of their scope (industry-wide as distinguished from plant-wide agreements). British agreements are less substantial than their counterparts in the United States, and, in particular, do not comprise anything like the American codes of job security and seniority or the grievance arbitration machinery through which these and other rights are enforced. On the other hand, Britain has nothing comparable with the German legislation on job security or the French principles on abusive or unfair dismissals. The Contract of Employment Act, 1963 , is no more than a foeble and insignificant first step in this direction: it gives a right to a maximum of four weeks' notice after five years of continuous employ. ment, and no power to award compensation for unfair deprivation of job. German workers and employees can claim up to one year's salary or wages by way of compensation for undue dismissal.

Similarly, Britain has neither the American pattern of grievance arbitration nor the Continental pattern of labour courts, consisting either (as in France) entirely of laymen, or (as in Germany) of a lawyer chairman, one employer and one employee with equal rights. These operate very rapidly and very cheaply, and settle many cases, and are far better adjusted to handling employer-employee cases than the existing machinery of justice in Britain.

To-day, British legislation on labour relations which, at one time, was in the van of progress, has fallen in arrears. The scrutiny of the fairness of dismissals, coupled with a power to award a right to be reinstated or to receive compensation and the creation of labour courts, are two measures necessary to promote social justice as well as the smooth operation of industrial relations.

The conference was also significant for a plea by Mr. G. R. Moxon (United Glass Ltd.), the president of the Institute, that the time had come for all bodies dealing with personnel management to re-examine their structure and organization and pool their resources in order to provide better services, particularly in projects overseas where British participation would be invaluable.

T. H. HAWKINS

\title{
SOLID-STATE CHEMISTRY
}

\begin{abstract}
$T$ HE phenomenal growth of solid-state chemistry in the past fifteen years owes much to the joint research ventures of chemists, engineers and physicists, and the impetus for this stems largely from what has been aptly tormed "the explosion in electronies", the invention of the transistor. In \& paper by Dr. N. B. Hannay, chemical director, Bell Telephone Laboratories, for many years past concerned with semiconductor chemistry (Science and Technology, New York; October, 1963), the present position of this intriguing subject is ably summarized. The basis of this discipline is, ho says, that "all solids are imperfect, fortunately, with atoms missing, misplaced, or of the wrong kind serving to bring the seemingly stolid solid to vibrant, useful, chemically reactive life". The high state of purity and crystalline perfection of some semiconductors, combined with their unique electrical properties, have facilitated the quantitative investigation of chemical processes in the solid state; they have made chemical reactions in such materials not only of great scientific interest but also to assume the importance of model systems as first principles in as yet a wide and largely unexplored field of chemical behaviour.

Many chemical interactions in semiconductors are analogous to those known and described in solution chemistry. The solvent is weakly ionized, like water, but in this caso solid instead of liquid. "Just as ionization of water produces hydroxide and hydrogen ions $\left(\mathrm{H}_{2} \mathrm{O} \rightleftarrows\right.$
\end{abstract}

$\left.\mathrm{H}^{+}+\mathrm{OH}^{-}\right)$so ionization in semiconductors produces conduction electrons and holes (Si lattice $\rightleftarrows \theta^{+}+\theta^{-}$) in a closely analogous way. Conduction electrons, which are not bound to any lattice atoms but wander freely through the lattice, are ereated when valence electrons are excited out of their normal atomic orbits by thermal agitation or by optical excitation. Holes, which simulate positively charged particles in their electrical behaviour, simply represent missing valence electrons". Several examples of reactions in semiconductors resembling those in aqueous solution are given in this paper and the anslogies between them are striking. They result from the essential similarity between the hole $\left(\theta^{+}\right)$-electron $\left(\theta^{-}\right)$equilibrium in semiconductors and the hydrogen-hydroxyl equilibrium in water. It is indicated that both equilibria are governed by the familiar law of mass action, that is, any change in concentration of reactents which are in equilibrium shifts the equilibrium in a direction that tends to neutralize the change.

As Dr. Hannay points out, there remain, apart from the 'glamorous' materials and devices already discovered in the course of these researches in solid-state chemistry, innumerable problems of major theoretical and practical importance that are still unsolved. Among these may be cited the better understanding of controls on reaction rates; diffusion mechanisms; nucleation processes, for example, as applicable to catalysis. H. B. Milner

\section{CENTENARY OF THE BIRTH OF W. H. YOUNG, F.R.S.}

$\mathrm{W}$ ILLTAM HENRY YOUNG was born on October 20, 1863. He entered Peterhouse, Cambridge, in 1881, was fourth Wrangler in 1884 and a Fellow of Peterhouse from 1886 until 1892 . For thirteen years he coached for the Mathematical Tripos, a profitable but arduous occupation. He was an excellent coach, particularly with less than excellent pupils, but he gave, so far as mathematics was concerned, no sign during this period of the fertile originality that was to come.

In 1896 he married Grace Chisholm, a mathematician of no mean ability herself, a Wrangler of Girton and the first woman D.Phil. of Göttingen. Distinguished as hor own work was, her greatest service to science was the influence she had on her husband, which, in the first instance, led him in 1897 to give up his Cambridge practice and dovote most of his time to research. From then on, the family home was abroad, at first in Göttingen, later in Switzerland. Although Young spent some months in each year from 1901 until 1923 in some paid activity, mainly teaching mathematics in Britain, mathematical research (unpaid) dominated the rest of his life. In 30 years he published more than 200 papers: Young burst out in British pure mathematics like a supernova. He was elocted a Fellow of the Royal Society in 1907.

His productivity is the more astounding in that it started so late and that his first work failed to bring him the credit it deserved. About this time, Lebesgue arrived at his definition of an integral. Young, working independently, arrived at a definition differing in form from Lebesgue's, but essentially equivalent. Lebesgue, how. 